\title{
Circular Polarized Dielectric Resonator Antenna for Portable RFID Reader Using a Single Feed
}

\author{
Regular Paper
}

\author{
Hend A. Malhat ${ }^{1 *}$, Saber H. Zainud-Deen ${ }^{2}$ and Kamal H. Awadalla ${ }^{3}$ \\ 1,2,3 Faculty of Electronic Engineering, Minoufiya University, Egypt \\ *Corresponding author E-mail: er_honida@yahoo.com \\ Received 28 May 2011; Accepted 21 June 2011
}

Abstract A new design of circular polarized elliptical dielectric resonator antenna (DRA) with single feed for handheld radio frequency identification (RFID) reader is presented. The elliptical dielectric resonator antenna with an aspect ratio of 1.5 is used. This design has achieved 66.7 MHz impedance bandwidth (for S11 <-10 $\mathrm{dB})$ by using material with dielectric constant material $\left(\varepsilon_{\mathrm{r}}=12\right)$ in conjunction with coaxial probe feed in free space. The DRA models are simulated using two different numerical techniques, the finite element method and the finite integral technique. The numerical results of the two different computational methods approache are investigated and compared. The results are in good agreement within the desired frequency band, $5.65 \mathrm{GHz}-5.95 \mathrm{GHz}$. A model for a handheld RFID reader device including the elliptical DRA in the presence of human hand models is, also, investigated. The return loss is $<10 \mathrm{~dB}$ over the frequency range of 5.49- $6.967 \mathrm{GHz}$ resulting in frequency bandwidth of $1.47 \mathrm{GHz}$. A high front to back ratio and gain of $5.726 \mathrm{dBi}$ are obtained.

Keywords Dielectric Resonator Antenna, RFID, Portable RFID Reader

\section{Introduction}

In recent years, radio frequency identification (RFID) has attracted a lot of attention and experienced strong growth in industrial applications [1-3]. A typical radio frequency identification system is made up of three components: an electronic data carrying device called RFID tag is combined with an antenna. The tag is usually an IC microchip which contains the items to be identified, a reader that communicates with the tag antenna by means of electromagnetic waves, and a host data processing system embodies the information of the identified item and communicates with other remote data processing systems. The RFID system covers frequency bands of low-band range $100-500 \mathrm{kHz}$, high frequency $13.56 \mathrm{MHz}$ and microwave band range $860-960 \mathrm{MHz}, 2.45 \mathrm{GHz}$ and $5.8 \mathrm{GHz}$. Examples include production, logistics, supply chain management, and asset tracking. Although RFID is often referred to as the next-generation barcode, one of the issues that troubles end-users is that RFID tags usually cannot be read with $100 \%$ accuracy in the real world due to factors such as limitations in the read range, tag orientation, or interference from water, metal, or other tags. A RFID reader is a radio transceiver: a transmitter and receiver that work together to communicate with the tag. The reader antenna must have high gain and 
directivity. A circularly polarized RFID reader antenna is generally required for various environments where omnidirectional tag reading is desired. To maximize tag read range, high gain antennas are typically used. Every additional $3 \mathrm{~dB}$ of reader antenna gain increase the tag range approximately by $40 \%$. While antennas for fixed reader installations can be relatively large, antennas for handheld RFID readers must be compact and ergonomically appealing. Making a compact high gain circularly polarized antenna is a challenging task. Most handheld readers use linearly polarized antennas or patch antennas for circular polarization [4-7]. The drawback of the patch antennas is narrow bandwidth. Dielectric resonator antennas (DRAs) have been developed for use in the microwave and millimeter frequency bands due to their attractive radiation characteristics. They offer several potential advantages such as small size, light weight, high radiation efficiency, wide bandwidth, low loss, and no excitation of surface waves. Usually DRAs are made of high dielectric constant materials with very low loss tangent. The low conduction loss makes them attractive for high frequency applications [8-11]. Different shapes of DRAs such as cylindrical, hemispherical, elliptical, pyramidal, rectangular, and triangular have been presented in the literature.

In this paper, a circularly polarized (CP) low-profile elliptical dielectric resonator antenna excited by a single probe $[12,13]$ for a handheld RFID reader is investigated. A dielectric material with $\varepsilon r=12$ is used as the main part of the antenna radiator. For excitation, a coaxial probe is used and placed off center of the antenna radiator. The DRA models are simulated using two different electromagnetic computational methods, the finite element method (FEM) [14, 15] and the finite integration technique (FIT) [16, 17]. A model for handheld reader device including the DRA antenna and the presence of the human hand model is presented. The DRA antenna radiation characteristics are calculated using FEM and compared with that calculated by FIT.

\section{Numerical Results}

Using the parametric study stated in [13], a circularly polarized elliptical DRA (EDRA) with a single probe feed is designed at $5.8 \mathrm{GHz}$ for portable RFID reader application. The antenna geometry is shown in Fig. 1. The radiating element has major axis radius ' $a$ ' of $5.6 \mathrm{~mm}$, and minor axis radius ' $b$ ' of $8.4 \mathrm{~mm}$, the aspect ratio $(a / b=1.5)$, and the height ' $\mathrm{Hd}$ ' is $5.6 \mathrm{~mm}$. The EDRA is mounted on square ground plane with edge length ' $\mathrm{L}$ ' of $60 \mathrm{~mm}$. A coaxial probe with radius $0.25 \mathrm{~mm}$ and height ' $h f^{\prime}$ of 4.8 $\mathrm{mm}$ is used to excite the DRA. The probe is located offcenter at $\left(\mathrm{W}_{\mathrm{x}}, \mathrm{W}_{\mathrm{y}}\right)$ of $(3.2 \mathrm{~mm}, 3.2 \mathrm{~mm})$. The computed frequency response of the return loss, $S_{11}$, and the input impedance are shown in Fig. 2 and Fig. 3. The results are calculated using FEM and compared with FIT and good agreement is obtained in the entire frequency band. The antenna has good impedance matching bandwidth extended from $5.64 \mathrm{GHz}$ to $6.32 \mathrm{GHz}$ for $\mathrm{S}_{11} \leq-10 \mathrm{~dB}$. The EDRA antenna exhibits good impedance matching with 50 ohm coaxial cable.

Figure 4 presents the simulated far-field radiation patterns of both co-polarization and cross-polarization for the designed antenna at resonant frequency $5.8 \mathrm{GHz}$. The presence of the perfectly conducting ground plane results in high front to back ratio of $26.5 \mathrm{~dB}$ in both the $\mathrm{x}-\mathrm{z}$ and $\mathrm{y}-$ $\mathrm{z}$ planes, also, the co-polar to cross-polar ratio is $17 \mathrm{~dB}$ at the resonance frequency. The frequency response of the axial ratio and gain are illustrated in Fig. 5a and Fig. 5b respectively. It is clearly seen that the LHCP bandwidth, determined from $3 \mathrm{~dB}$ axial ratio, is $2.7 \%(160 \mathrm{MHz})$ with respect to the centre frequency $5.8 \mathrm{GHz}$. The antenna gain ranges from $2.96 \mathrm{~dB}$ at $4 \mathrm{GHz}$ to $4.95 \mathrm{~dB}$ at $7 \mathrm{GHz}$, and $6.51 \mathrm{~dB}$ over the whole RFID band from 5.65 to $5.95 \mathrm{GHz}$.

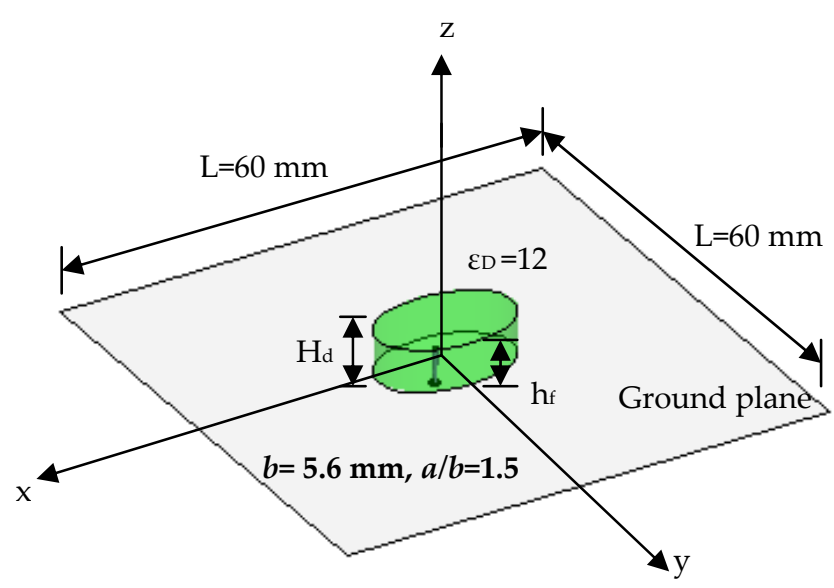

a. 3-D view of the antenna

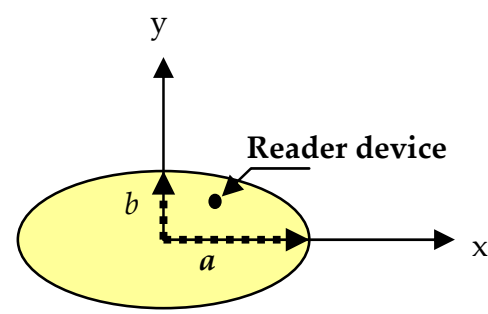

b. 2-D view of the radiating element

Figure 1. The CP- EDRA Antenna structure in free space 


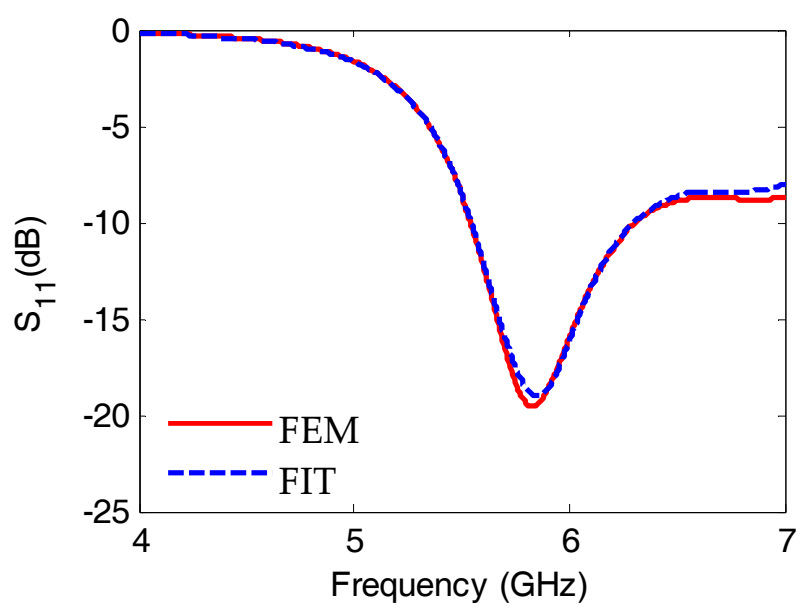

Figure 2. The return loss of the CP-EDRA over finite size ground plane in free space.

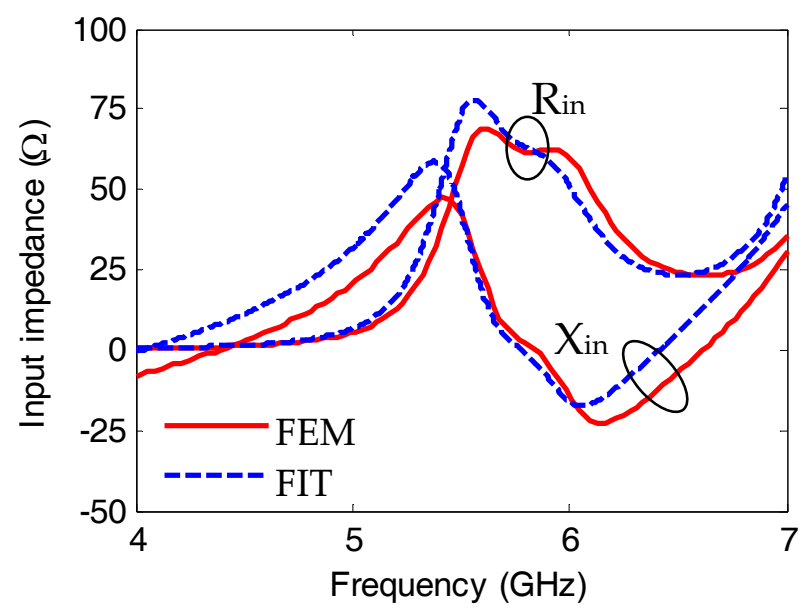

Figure 3. The input impedance of the CP-EDRA over finite size ground plane in free space.

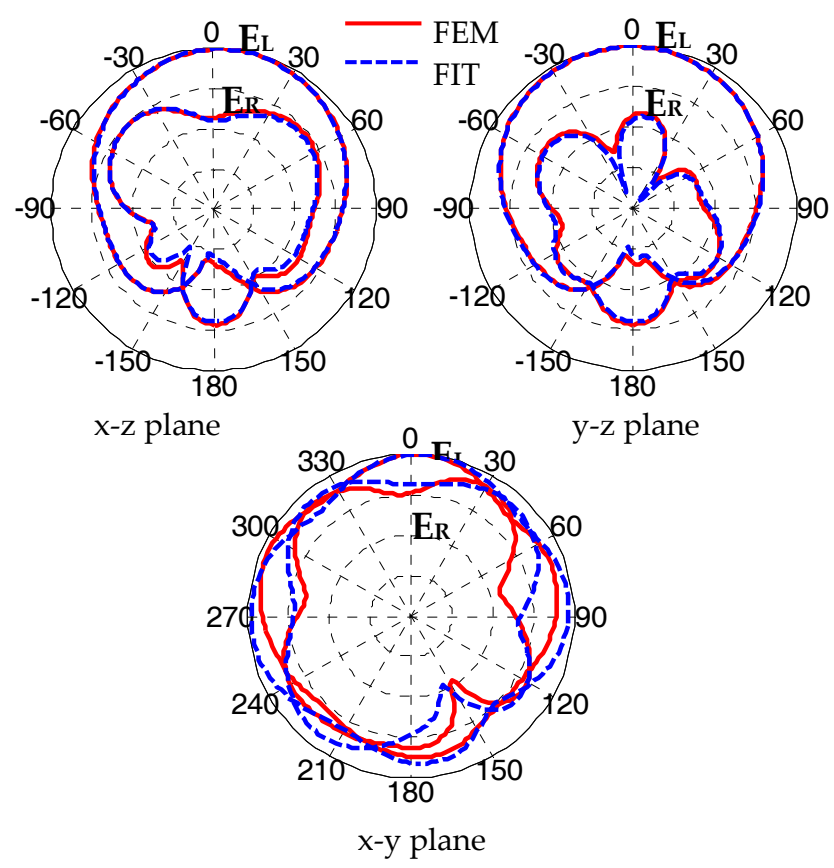

Figure 4. The circular polarization radiation patterns of the CP-EDRA in free space.

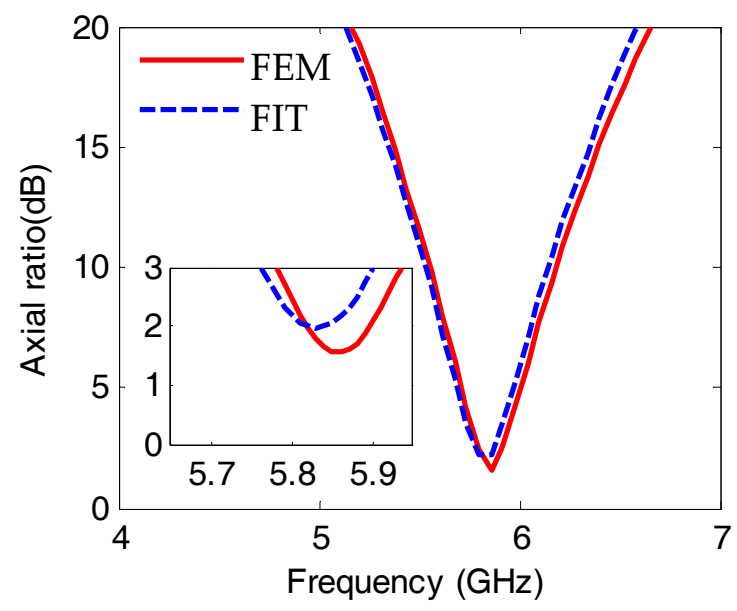

a. The axial ratio

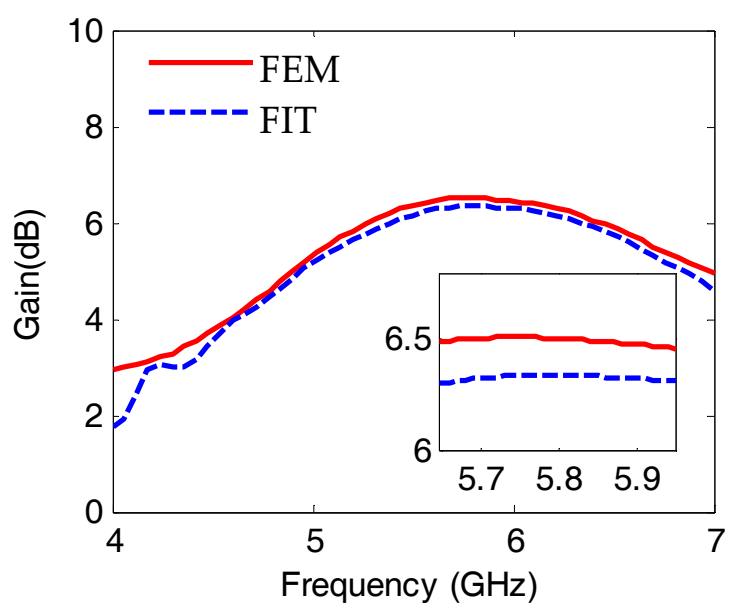

b. Gain

Figure 5. The axial ratio and the antenna gain of the CP-EDRA in free space.

A proposed model for handheld reader device and human hand with an EDRA the antenna placed on the reader device is shown in Fig. 6. The hand held reader device is dielectric plastic material of $\varepsilon \mathrm{D}=2.8$ and tan $\delta \mathrm{D}=0.001 \mathrm{~S} / \mathrm{m}$ (at $900 \mathrm{MHz}$ ). The detailed dimensions are presented in Table 1. The presented model is designed to obtain main beam in the $\mathrm{z}$-axis direction. The handheld reader and human hand model are arranged in order to reduce the electromagnetic radiation towards the human operator, also reducing the effect of the reader device and human operator on the radiation characteristics of the antenna. Figure 7 shows the simulated return loss of the EDRA mounted on the reader device in the presence of a human hand model. The antenna input impedance versus frequency is presented on Fig. 8. Good impedance matching is obtained. The impedance matching bandwidth range for return loss less than $-10 \mathrm{~dB}$ is 5.49$6.967 \mathrm{GHz}(25.36 \%)$ resulting in frequency bandwidth of $1.47 \mathrm{GHz}$. 

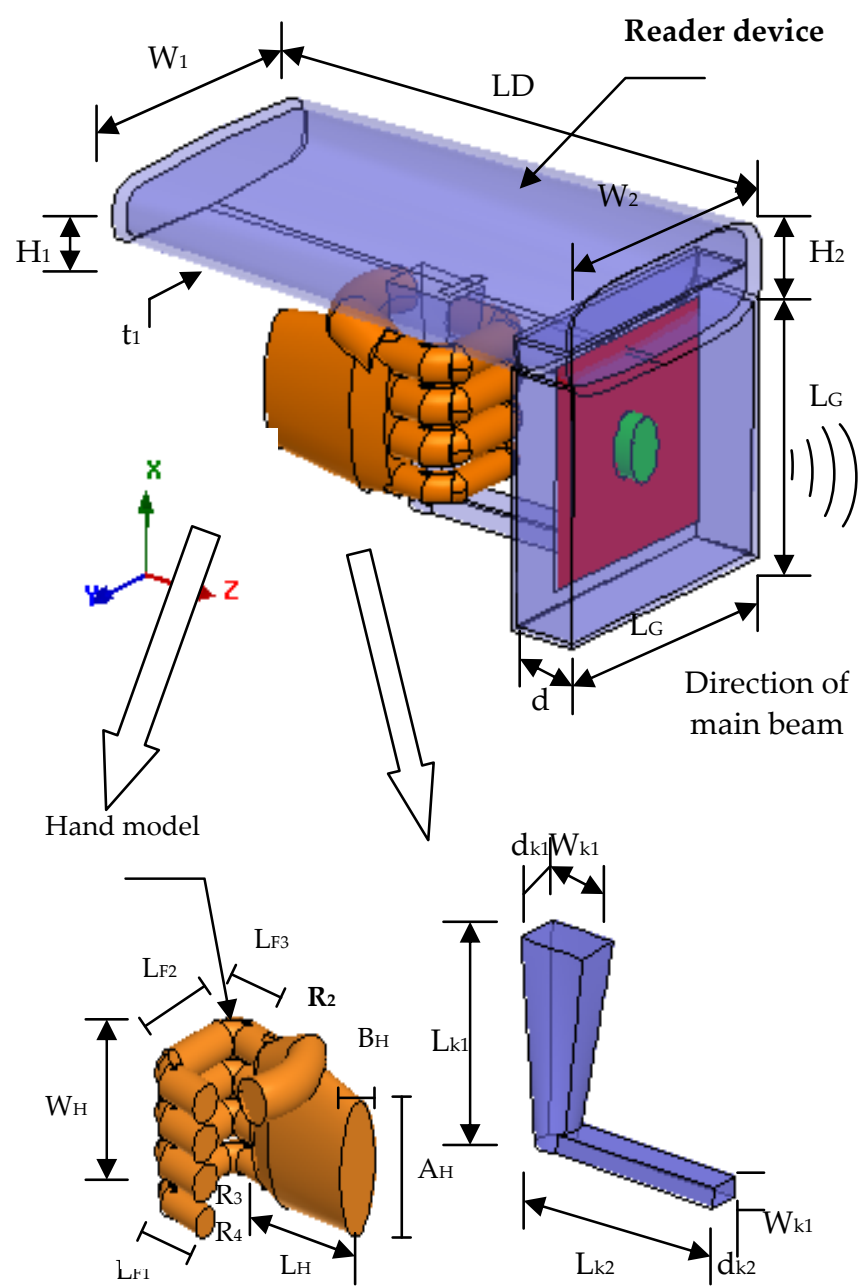

Figure 6. The detailed dimensions of the DRA antenna in the presence of handheld reader device and human hand model.

\begin{tabular}{|c|c|c|c|}
\cline { 2 - 4 } $\mathrm{W}_{1}$ & $8 \mathrm{~cm}$ & $\mathrm{~L}_{4}$ & $2.4 \mathrm{~cm}$ \\
$\mathrm{H}_{1}$ & $3 \mathrm{~cm}$ & $\mathrm{~W}_{4}$ & $1.5 \mathrm{~cm}$ \\
$\mathrm{~W}_{2}$ & $8 \mathrm{~cm}$ & $\mathrm{R}_{1}$ & $0.9 \mathrm{~cm}$ \\
$\mathrm{H}_{2}$ & $2 \mathrm{~cm}$ & $\mathrm{AH}_{\mathrm{H}}$ & $10 \mathrm{~cm}$ \\
$\mathrm{LD}$ & $15 \mathrm{~cm}$ & $\mathrm{BH}_{\mathrm{H}}$ & $4.5 \mathrm{~cm}$ \\
$\mathrm{t}_{1}$ & $0.2 \mathrm{~cm}$ & $\mathrm{LH}_{\mathrm{H}}$ & $7 \mathrm{~cm}$ \\
$\mathrm{LG}_{\mathrm{g}}$ & $7.8 \mathrm{~cm}$ & $\mathrm{~W}_{\mathrm{H}}$ & $6 \mathrm{~cm}$ \\
$\varepsilon_{\mathrm{D}}$ & $2.8(900 \mathrm{MHz})$ & $\mathrm{R}_{2}$ & $0.6 \mathrm{~cm}$ \\
$\tan \delta_{\mathrm{H}}$ & $0.001 \mathrm{~S} / \mathrm{m}(900 \mathrm{MHz})$ & $\mathrm{R}_{3}$ & $0.5 \mathrm{~cm}$ \\
$\mathrm{~d}$ & $2 \mathrm{~cm}$ & $\mathrm{R}_{4}$ & $0.4 \mathrm{~cm}$ \\
$\tan \delta \mathrm{D}$ & $0.01 \mathrm{~S} / \mathrm{m}(900 \mathrm{MH})$ & $\mathrm{LF}_{1}$ & $2 \mathrm{~cm}$ \\
$\varepsilon_{\mathrm{H}}$ & $20(900 \mathrm{MHz})$ & $\mathrm{LF}_{2}$ & $2.5 \mathrm{~cm}$ \\
$\mathrm{~W}_{3}$ & $2.4 \mathrm{~cm}$ & $\mathrm{LF}_{3}$ & $1.5 \mathrm{~cm}$ \\
$\mathrm{t}_{2}$ & $0.3 \mathrm{~cm}$ & $\Phi_{1}$ & $90^{\circ}$ \\
$\mathrm{H}_{3}$ & $5 \mathrm{~cm}$ & $\Phi_{2}$ & $30^{\circ}$ \\
\hline
\end{tabular}

Table 1. The dimensions of handheld reader device and human hand model.

Figure 9 shows the far-field radiation patterns of both copolarized and cross-polarized field components for the designed antenna at resonant frequency $5.8 \mathrm{GHz}$. Due to the presence of the EDRA mounted on perfect conducting ground plane, the field in the back direction is reduced (high front to back ratio). Thus the presence of the reader device and human hand model will have nearly little effect on the radiation characteristics of the EDRA. Thus with this reader and antenna arrangement, the size and other simulated layered human hand model parameters will has no effect on the antenna performance. Figure 10a exhibits the simulated AR in the direction of the main beam versus frequency. The 3-dB AR bandwidth of $5.716-5.903 \mathrm{MHz}$ or $3.23 \%(187 \mathrm{MHz})$ relative to the resonance frequency is obtained. The simulated boresight gain is illustrated in Fig. 10b. The antenna exhibits peak gain of $5.726 \mathrm{~dB}$ at $5.8 \mathrm{GHz}$ which is not much reduced compared with that of the antenna in free space. The slight reduction in gain is due to, the antenna mounting on the reader device which act as a superstrate layer on the EDRA antenna, thus the total effective relative dielectric constant is changed.

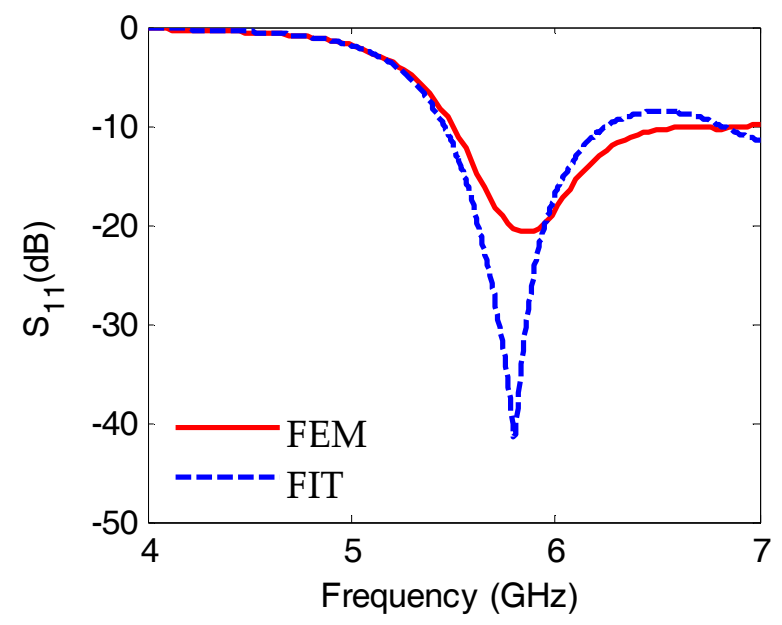

Figure 7. The return loss of the DRA in the presence of handheld reader device and human hand model.

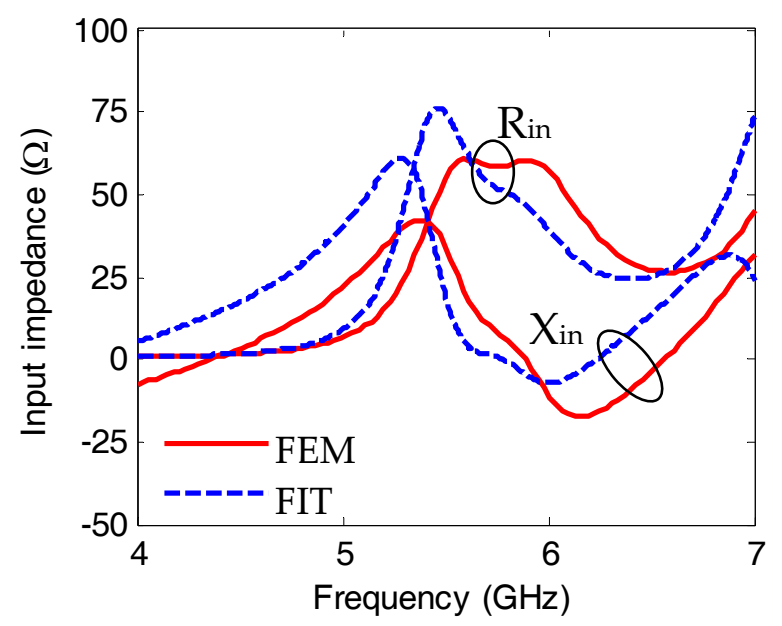

Figure 8. The input impedance of the DRA in the presence of handheld reader device and human hand model. 

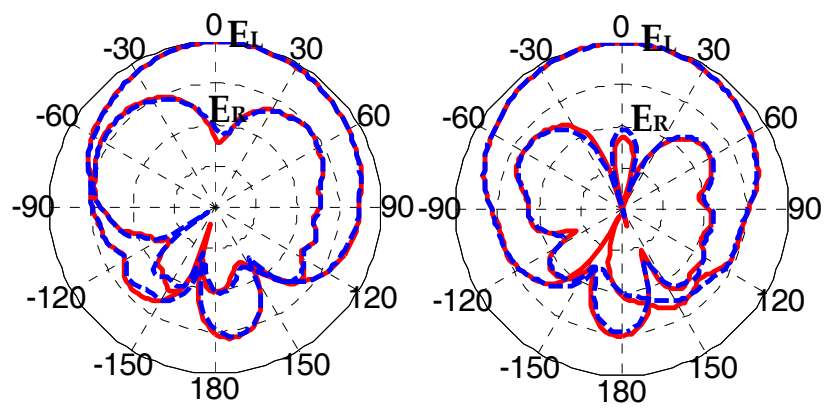

$\mathrm{x}-\mathrm{z}$ plane

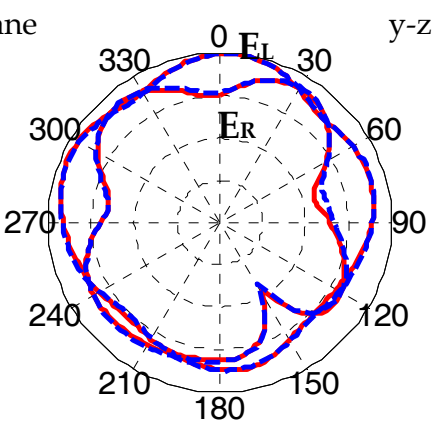

$\mathrm{x}-\mathrm{y}$ plane

Figure 9. The circular polarization radiation pattern of the DRA antenna in the presence of handheld reader device and human hand model.

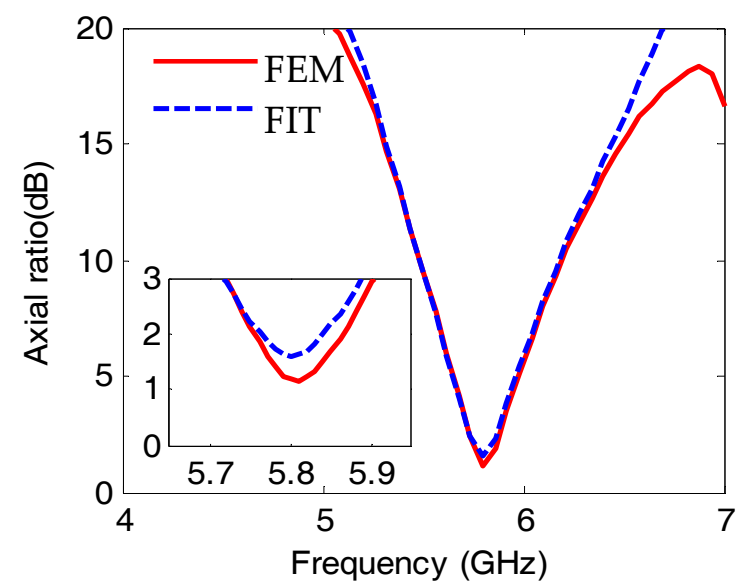

a. The axial ratio

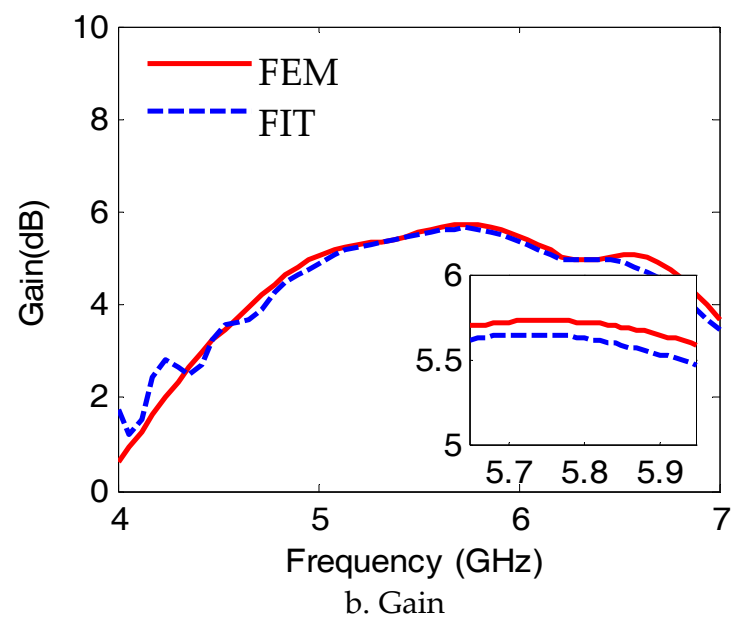

Figure 10. The axial ratio and the antenna gain of the DRA in the presence of handheld reader device and human hand model.

\section{Conclusion}

In this paper, an elliptical dielectric resonator antenna fed by single feed with rectangular ground is proposed for radio frequency identification (RFID) reader operating at center frequency of $5.8 \mathrm{GHz}$. The antenna is modeled and simulated using the FEM and compared with the FIT results in free space and good agreement is obtained. The antenna impedance bandwidth is $66.7 \mathrm{MHz}$ with high front to back ratio. The circular polarization band width $(A R<3 \mathrm{~dB})$ is 160 $\mathrm{MHz}$ with peak gain of $6.51 \mathrm{~dB}$. The effects of the presence of portable reader device and human hand on the radiation characteristics of the antenna are investigated. The results show that the proposed position of the reader device and the human hand model didn't affects the performance of the antenna. A broader impedance bandwidth of $1.47 \mathrm{GHz}$ is obtained. A high forward radiation gain and a strong suppression of backward radiation are obtained.

\section{References}

[1] K. Finkenzeller, RFID Handbook: Radio- Frequency Identification Fundamentals and Applications, $2^{\text {nd }}$ ed., Wiley \& Sons, Inc., New Jersey, USA, 2004.

[2] V. D. Hunt, A. Puglia, and M. Puglia, RFID: A Guide to Radio Frequency Identification, Wiley $\mathcal{E}$ Sons, Inc., New Jersey, USA, 2007.

[3] G. Marrocco, “The art of UHF RFID antenna design: impedance- matching and size- reduction techniques," in Proc. IEEE Antennas and Propagation Magazine., Vol. 50, No. 1, pp. 1-21, Feb. 2008.

[4] S. A. Yeh, H. M. Chen, Y. F. Lin, Y. C. Kao, and J. Y. Jan, "Single-layer circularly polarized slot antenna for RFID reader application," in Proc. IEEE Antennas and Propagation Soc. Int. Symp., Vol. 1, June 2010.

[5] F. Y. Kuo, and H. T. Hsu, "Aperture-coupled patch array antenna for microwave band RFID handheld reader," in Proc. IEEE Antennas and Propagation Soc. Int. Symp., Vol. 1, June 2010.

[6] H. L. Chung, X. Qing, and Z. N. Chen, “Broadband circularly polarized stacked patch antenna for UHF RFID applications," in Proc. IEEE Antennas and Propagation Soc. Int. Symp., Vol. 1, pp. 1189-1192, June 2007.

[7] L. Ukkonen, M. Schäffrath, M. Engels, D. W. Sydanheimo, and M. Kivikoski, "Operability of folded microstrip patch-type tag antenna in the UHF RFID bands within 865-928 MHz", IEEE Antennas Wireless Propag. Lett., Vol. 5, No. 1, pp. 414-417, 2006.

[8] K. M. Leung, and K. W. Luk, Dielectric Resonator Antenna, Research Studies Press LTD., Hertfordsire, England, 2003.

[9] S. H. Zainud-Deen, H. A. Malhat, and K. H. Awadalla," Dielectric resonator antenna mounted on a circular cylindrical ground plane," Progress In Electromagnetics Research B, PIER B, Vol. 19, pp. 427-444, 2010. 
[10] S. H. Zainud-Deen, H. A. Malhat, and K. H. Awadalla," Cylindrical dielectric resonator antenna housed in a shallow cavity in a hollow circular cylindrical ground plane." $26^{\text {rd }}$ Applied Computational Electromagnetics Society (ACES) Conference, Tampere, Finland, April 26-29, 2010.

[11] A. Petosa, Dielectric Resonator Antenna Handbook, Artech House, Inc., Norwood, USA, 2007.

[12] A. Kisk, “An Elliptical Dielectric Resonator Antenna Designed For Circular Polarization with Single Feed" Microwave and Optical Technology Letters, Vol. 37, No. 6, pp. 454- 456, June 2003.

[13] S. H. Zainud- Deen, H. A. Malhat, and K. H. Awadalla, "A single feed cylindrical superquadric dielectric resonator antenna for circular polarization," Progress In Electromagnetics Research, PIER 85, pp. 409- 424, 2008.
[14] J. L. Volakis, A. Chatterjee, L. C. Kempel, Finite Element Method for Electromagnetics : Antennas, Microwave Circuits, and Scattering Applications, Piscataway, NJ, IEEE Press, USA, 1998.

[15] A. C. Polycarpou, Introduction to the Finite Element Method in Electromagnetics, Morgan \& Claypool, USA, 2006.

[16] T. Weiland, "A discretization method for the solution of Maxwell's equations for six- component fields," Electromagnetics and Communications AEÜ, Vol. 31, No. 3, pp. 116-120, March 1977.

[17] M. Clemens, and T. Weiland, "Discrete electromagnetism with the finite integration technique," Progress In Electromagnetics Research, PIER, Vol. 32, pp. 65- 87, 2001. 